\title{
Abnormality of Aldosterone and Cortisol Late Pathways in Glucocorticoid-Remediable Aldosteronism
}

\author{
FRANCESCO FALLO, URSULA KUHNLE, MARCO BOSCARO, \\ AND NICOLETTA SONINO \\ Division of Endocrinology, Institute of Semeiotica Medica, University of Padova (F.F., M.B., N.S.), 35128 \\ Padova, Italy; and Universitatskinderklinik (U.K.), D-8000 Munich 2, Germany
}

\begin{abstract}
Patients with glucocorticoid-remediable aldosteronism (GRA) possess a chimeric gene resulting from fusion of the genes encoding steroid aldosterone synthase and $11 \beta$-hydroxylase. In the adrenal zona fasciculata, this may lead to ectopic expression under ACTH control of aldosterone synthase activity and increased formation of cortisol $\mathrm{C}_{18}$ oxidation products. We assessed mineralocorticoid and glucocorticoid pathways in three patients with GRA. Baseline plasma progesterone, $17 \alpha$-hydroxyprogesterone, corticosterone, and cortisol were normal in all patients, whereas 11-deoxycorticosterone, aldosterone, and 11-deoxycortisol were above normal. The ratios of both corticosterone/11-
\end{abstract}

deoxycorticosterone and cortisol/11-deoxycortisol were abnormally low, and decreased further $60 \mathrm{~min}$ after administration of ACTH-(124) $(250 \mu \mathrm{g})$ as an iv bolus. A low corticosterone/11-deoxycorticosterone ratio is consistent with an increased aldosterone synthase activity forming aldosterone by corticosterone. Similarly, a decreased cortisol/ 11-deoxycortisol ratio could reflect enhanced cortisol $\mathrm{C}_{18}$ oxidation. Our findings are in agreement with a hyperfunction of the $11 \beta$-hydroxylase/aldosterone synthase complex in the adrenal zona fasciculata of GRA induced by the new chimeric gene. ( $J$ Clin Endocrinol Metab 79: $772-774,1994)$
G LUCOCORTICOID -remediable aldosteronism (GRA) is an ACTH-dependent autosomal dominant form of mineralocorticoid hypertension in which the excessive aldosterone production and clinical syndrome are corrected by the administration of glucocorticoids $(1,2)$. The genetic abnormality has recently been described $(3,4)$; the mutation results from fusion of the genes encoding steroid $11 \beta$-hydroxylase and aldosterone synthase. In the adrenal zona fasciculata, this may lead to ectopic expression under ACTH control of aldosterone synthase activity, which normally catalizes both corticosterone and 18-hydroxycorticosterone methyl oxidations in the zona glomerulosa. A specific biochemical abnormality of this disease is, in fact, the overproduction of cortisol $C_{18}$ oxidation metabolites (5-7). Scattered data are available on precursor steroids of aldosterone and cortisol in this disease. In particular, whereas aldosterone precursors are reported variably high $(8-10)$ or normal $(11,12)$, cortisol precursors have been found in the normal range $(7,13)$. We studied three patients with GRA, assessing mineralocorticoid and glucocorticoid pathways both under baseline conditions and after ACTH stimulation.

\section{Subjects and Methods}

Three siblings (patient 1 , female, aged $19 \mathrm{yr}$; and patients 2 and 3 , males, aged 23 and $35 \mathrm{yr}$, respectively) in a family of nine siblings were shown to have GRA. The family pedigree and a detailed biochemical and hormonal assessment of all family members have been previously reported (14). The chimeric bands analyzed by Southern blot in leuko-

Received February 16, 1994. Revision received April 13, 1994. Accepted May 11, 1994.

Address all correspondence and requests for reprints to: $F$. Fallo, M.D., Division of Endocrinology, Institute of Semeiotica Medica, University of Padova, Via Ospedale 105, 35128 Padova, Italy. cyte DNA indicating the genetic abnormality in patients 1 and 2 have been reported previously (15), whereas in patient 3 this genetic study was not performed. Hormonal evaluation was conducted under baseline conditions before glucocorticoid treatment while patients received a normal sodium (150 mmol/day) and potassium (60 mmol/day) diet. All three patients were hypertensive and hypokalemic at the time of the study. Urinary sodium excretion was 136,142 , and $140 \mathrm{mmol} /$ day in patients 1,2 , and 3 , and urinary potassium excretion was 74,66 , and $70 \mathrm{mmol} /$ day in patients 1,2 , and 3 , respectively. As previously reported (16), urinary products of cortisol $C_{18}$ oxidation 18-oxocortisol (as the tetrahydro derivative) and 18-hydroxycortisol, measured by gas chromatography-mass spectrometry, were very high (18-oxotetrahydrocortisol: 154, 356, and $608 \mathrm{nmol} /$ day; normal mean $\pm \mathrm{sD}, 7 \pm 5 \mathrm{nmol} /$ day; 18-hydroxycortisol, 1048, 2768, and $2943 \mathrm{nmol} /$ day; normal, $110 \pm 60$ $\mathrm{nmol} /$ day in patients 1,2 , and 3 , respectively). Plasma levels of progesterone, 11-deoxycorticosterone, corticosterone, aldosterone, 17 $\alpha$-hydroxyprogesterone, 11-deoxycortisol, and cortisol were measured at $0900 \mathrm{~h}$ after a $30-\mathrm{min}$ rest in an armchair, before and $60 \mathrm{~min}$ after ACTH-(1-24) administration (Synacthen, Ciba, Basel, Switzerland; 250 $\mu \mathrm{g}$ as an iv bolus). Four unaffected siblings of the family underwent the same hormonal evaluation. Twenty healthy subjects (10 males and 10 females, aged 17-44 yr) were used as normal controls. All plasma steroids were measured by the method of Sippell et al. (17), using mechanized Sephadex LH-20 multiple column chromatography and specific RIAs. For normal values, see Table 1.

\section{Results}

Plasma steroid results are reported in Table 1. Baseline progesterone, corticosterone, $17 \alpha$-hydroxyprogesterone, and cortisol levels were normal in all three patients and responded normally to ACTH standard stimulation test. Baseline and ACTH-stimulated 11-deoxycorticosterone, aldosterone, and 11-deoxycortisol levels were above normal. Both baseline corticosterone/11-deoxycorticosterone and cortisol/ 11-deoxycortisol ratios, expressed on an equimolar basis, were abnormally low [24, 19, and 12 (normal range, 46-78) and 17,13 , and 12 (normal range, 158-210), respectively] 
TABLE 1. Plasma steroid levels in the three patients with GRA and normal controls before and after ACTH treatment

\begin{tabular}{|c|c|c|c|c|c|c|c|}
\hline & $P(\mathrm{nmol} / \mathrm{L})$ & $\underset{(\mathrm{nmol} / \mathrm{L})}{\mathrm{DOC}}$ & $\mathrm{B}(\mathrm{nmol} / \mathrm{L})$ & $\begin{array}{c}\text { ALDO } \\
(\mathrm{pmol} / \mathrm{L})\end{array}$ & $\begin{array}{c}\text { 17-OHP } \\
(\mathrm{nmol} / \mathrm{L})\end{array}$ & $\mathrm{S}(\mathrm{nmmol} / \mathrm{L})$ & $F(\mathrm{nmol} / \mathrm{L})$ \\
\hline \multicolumn{8}{|l|}{ Patient 1} \\
\hline Baseline & 0.58 & 0.37 & 9.02 & 416.8 & 2.3 & 13.2 & 221.2 \\
\hline ACTH & 2.49 & 4.55 & 87.1 & 1156 & 7.0 & 43.1 & 594.0 \\
\hline \multicolumn{8}{|l|}{ Patient 2} \\
\hline Baseline & 0.66 & 0.46 & 8.82 & 341.2 & 3.7 & 14.1 & 181.8 \\
\hline ACTH & 2.27 & 5.72 & 47.9 & 890.2 & 11.0 & 78.3 & 380.7 \\
\hline \multicolumn{8}{|l|}{ Patient 3} \\
\hline Baseline & 0.28 & 0.37 & 4.46 & 205.4 & 2.6 & 14.5 & 178.8 \\
\hline ACTH & 1.80 & 5.22 & 52.4 & 818.3 & 8.7 & 77.7 & 525.0 \\
\hline \multicolumn{8}{|c|}{ Normal subjects $(n=20)$} \\
\hline Baseline & $0.45 \pm 0.3$ & $0.13 \pm 0.04$ & $8.42 \pm 5.1$ & $124.2 \pm 27$ & $2.4 \pm 0.8$ & $1.65 \pm 0.7$ & $281.4 \pm 99$ \\
\hline ACTH & $1.51 \pm 0.5$ & $1.54 \pm 0.27$ & $97.4 \pm 36.2$ & $196.8 \pm 66$ & $6.4 \pm 2.1$ & $6.7 \pm 1.5$ & $642.8 \pm 151$ \\
\hline
\end{tabular}

P, Progesterone; DOC, 11-deoxycorticosterone; B, corticosterone; ALDO, aldosterone; 17-OHP, 17 $\alpha$-hydroxyprogesterone; S, 11-deoxycortisol; F, cortisol.

and decreased further after ACTH-(1-24) administration [19, 8 , and 10 (normal range, 52-84) and 14,5 , and 7 (normal range, 104-153), respectively]. Four unaffected siblings of the family showed no steroid abnormalities either under baseline conditions or after ACTH stimulation (data not shown).

\section{Discussion}

Recently, fusion genes generated by unequal cross-over were identified as the underlying cause of GRA in 16 kindreds, including ours (15). The gene is a hybrid with a 5 '-regulatory ACTH-responsive region of the gene encoding for isoenzyme CYP11B1 (P450c11), which mediates the last step of cortisol synthesis, $11 \beta$-hydroxylation, and the $3^{\prime}$ coding region of the gene encoding for isozyme CYP11B2 (P450aldo synthase), which mediates the final three steps of aldosterone synthesis, $11 \beta$ - and 18-hydroxylation, and 18oxidation $(3,4,18)$. These two P450 enzymes are normally encoded by twin genes on chromosome 8 and share greater than $90 \%$ homology (19). The biochemical consequence of the genetic rearrangement in GRA is the formation of aldosterone under ACTH drive by the zona fasciculata, together with 18-hydroxy- and 18-oxocortisol formation from the methyl oxidation of cortisol. Interestingly, both baseline and ACTH-stimulated 11-deoxycorticosterone and 11-deoxycortisol were above normal in our cases, suggesting hyperresponsivity of the zona fasciculata to $\mathrm{ACTH}$, involving multiple steroidogenic steps. Overproduction of sodium-retaining steroids other than aldosterone has been advocated to explain the dramatic effect of increasing blood pressure in these patients after prolonged ACTH administration (20). However, due to abnormal adrenal zonation, it is not possible to separate mineralocorticoid and glucocorticoid pathways in the absence of glucocorticoid treatment.

The ratios of plasma concentrations of corticosterone to 11-deoxycorticosterone and cortisol to 11-deoxycortisol are considered an indirect assessment of $11 \beta$-hydroxylase activity (21), i.e. increased function of this enzyme corresponds to decreased ratios due to enhanced formation of end products. Accordingly, both of these ratios were below normal in our patients, in whom an accelerated metabolism of corticos- terone and cortisol, due to abnormal sensitivity of $11 \beta$ hydroxylase/aldosterone synthase to endogenous $\mathrm{ACTH}$, occurred. Moreover, exogenous ACTH administration further lowered both corticosterone/11-deoxycorticosterone and cortisol/11-deoxycortisol ratios, confirming the marked ACTH dependence of cortisol metabolites (22) and aldosterone (14, 23) as a typical feature of GRA. In conclusion, our data are in agreement with a hyperfunction of the $11 \beta$-hydroxylase/ aldosterone synthase complex in the adrenal zona fasciculata induced by the new chimaeric gene in this disorder.

\section{References}

1. Sutherland DIA, Ruse JL, Laidlaw JC. 1966 Hypertension, increased aldosterone secretion and low plasma renin activity relieved by dexamethasone. Can Med Assoc J. 95:1109-1119.

2. Fallo F, Mantero F. 1990 Dexamethasone-suppressible hyperaldosteronism. In: Biglieri EG, Melby JC, eds. Endocrine hypertension Comprehensive endocrinology, revised series. New York: Raven Press; 87-98

3. Lifton RB, Dluhy RG, Powers $M$, et al. 1992 A chimaeric $11 \beta$ hydroxylase/aldosterone synthase gene causes glucocorticoid remediable aldosteronism and human hypertension. Nature. 35:262265.

4. Pascoe L, Curnow KM, Slutsker L, et al. 1992 Glucocorticoidsuppressible hyperaldosteronism results from hybrid genes created by unequal crossovers between CYP11B1 and CYP11B2. Proc Nat Acad Sci USA. 89:8327-8331.

5. Ulick S, Chu MD. 1982 Hypersecretion of a new corticosteroid, 18 hydroxycortisol, in two types of adrenocortical hypertension. Clin Exp Hypertension. A4(9 and 10):1771-1777.

6. Gomez-Sanchez CE, Montgomery M, Ganguly A, et al. 1984 Elevated urinary excretion of 18-oxocortisol in glucocorticoid-suppressible hyperaldosteronism. J Clin Endocrinol Metab. 59:10221024.

7. Rich GM, Ulick S, Cook S, Wang JZ, Lifton RP, Dluhy RG. 1992 Glucocorticoid-remediable aldosteronism in a large kindred: clinical spectrum and diagnosis using a characteristic biochemical phenotype. Ann Intern Med. 116:813-820.

8. Rauh W, Levine LS, Gottesdiener K, New MI. 1978 Mineralocorticoids, salt balance and blood pressure after prolonged ACTH administration in juvenile hypertension. Klin Wochenschr. 56(Suppl 1):161-168.

9. Oberfield SE, Levine LS, Stoner E, et al. 1981 Adrenal glomerulosa function in patients with dexamethasone-suppressible hyperaldosteronism. J Clin Endocrinol Metab. 53:158-164.

10. Connell JMC, Kenyon CJ, Corrie JET, et al. 1986 Dexamethasonesuppressible hyperaldosteronism: adrenal transition cell hyperplasia? Hypertension. 8:669-676. 
11. Giebink GS, Gotlin RW, Biglieri EG, Katz FH. 1973. A kindred with familial-glucocorticoid-suppressible hyperaldosteronism. J Clin Endocrinol Metab. 36:715-723.

12. Grim CE, Weinberger MH. 1980 Familial dexamethasone-suppressible hyperaldosteronism. Pediatrics. 65:597-604.

13. Stockigt JR, Scoggins BA. 1987 Long term evolution of glucocorticoid-suppressible hyperaldosteronism. J Clin Endocrinol Metab. 98:87-89.

14. Fallo F, Sonino N, Armanini D, et al. 1985 A new family with dexamethasone-suppressible hyperaldosteronism: aldosterone unresponsiveness to angiotensin II. Clin Endocrinol (Oxf). 22:777-785.

15. Lifton RP, Dluhy RG, Powers M, et al. 1992 Hereditary hypertension caused by chimaeric gene duplications and ectopic expression of aldosterone synthase. Nature Genet. 2:66-74.

16. Ulick S, Chan CK, Gill Jr JR, et al. 1990 Defective fasciculata zone function as the mechanism of glucocorticoid-remediable aldosteronism. J Clin Endocrinol Metab. 71:1151-1157.

17. Sippell WG, Bidlingmaier F, Becker $\mathrm{H}$, et al. 1978 Simultaneous radioimmunoassay of plasma aldosterone, corticosterone, 11-deoxycorticosterone, progesterone, 17-hydroxyprogesterone, 11-deoxy- cortisol, cortisol and cortisone. J Steroid Biochem. 9:63-78.

18. Curnow KM, Tusie-Luna MT, Pascoe L, et al. 1991 The product of the CYP11B2 gene is required for aldosterone biosynthesis in the human adrenal cortex. Mol Endocrinol. 5:1513-1522.

19. Mornet E, Dupont J, Vitek A, White PC. 1989 Characterization of two genes encoding human steroid $11 \beta$-hydroxylase $\left(\mathrm{P}-450_{11 \beta}\right)$. J Biol Chem. 264:20961-20967.

20. New MI, Peterson RE, Saenger P, Levine LS. 1976 Evidence for an unidentified ACTH-induced steroid hormone causing hypertension. J Clin Endocrinol Metab. 43:1283-1293.

21. Ganguly A, Meikle AW, Tyler FH, West CD. 1977 Assessment of $11 \beta$-hydroxylase activity with plasma corticosterone, deoxycorticosterone, cortisol, and deoxycortisol: role of ACTH and angiotensin. J Clin Endocrinol Metab. 44:560-568.

22. Gomez-Sanchez CE, Gill Jr JR, Ganguly A, Gordon RD. 1988 Glucocorticoid-suppressible hyperaldosteronism: a disorder of the adrenal transitional zone. J Clin Endocrinol Metab. 67:444-448.

23. Ganguly A, Weinberger MH, Guthrie GP, Fineberg NS. 1984 Adrenal steroid response to $\mathrm{ACTH}$ in glucocorticoid-suppressible hyperaldosteronism. Hypertension. 6:563-567. 